\title{
UPAYA GURU DALAM MENINGKATKAN KECERDASAN INTERPERSONAL SISWA DI SDIT TAQIYYA ROSYIDA KARTASURA TAHUN AJARAN 2019/2020
}

\author{
Rofiiqoh Jamiil \\ MI Muhammadiyah Wangen \\ E-mail: rofiiqoh.jamiil.998@gmail.com
}

\begin{abstract}
Interpersonal intelligence needs to be developed to form individual characters who can work together with others. The purpose of this study is to measure the wise in improving the interpersonal intelligence of students at SDIT Taqiyya Rosyida Kartasura. This type of research is a qualitative descriptive study. This research was started from November 2019 to July 2020, at SDIT Taqiyya Rosyida Kartasura. Data through observation, interviews, and documentation and analyzed by interactive models. The results showed the efforts made by SDIT Taqqiya Rosyida teacher to improve interpersonal intelligence, namely: 1) the application of 15 adab habituation, online through holiday challenges; 2) provide motivation to students through storytelling activities, when online learning provides motivation only in the form of advice; 3) class management; 4) approach independently or in groups; 5) implementation of learning strategies that involve collaboration between students; and 6) application of visual and audio-visual learning media
\end{abstract}

Keywords: Interpersonal Intelligence; Primary School Student

\begin{abstract}
Abstrak Kecerdasan interpersonal perlu dikembangkan untuk membentuk karakter individu yang dapat bekerjasama dengan orang lain. Tujuan penelitian ini adalah untuk mengetahui upaya guru dalam meningkatkan kecerdasan interpersonal siswa di SDIT Taqiyya Rosyida Kartasura. Jenis penelitian ini adalah penelitian deskripsif kualitatif. Penelitian ini dimulai bulan November 2019 sampai Juli 2020, di SDIT Taqiyya Rosyida Kartasura. Data dikumpulkan melalui observasi, wawancara, dan dokumentasi dan dianalisis dengan model interaktif. Hasil penelitian menunjukkan beberapa upaya yang dilakukan guru SDIT Taqqiya Rosyida untuk meningkatkan kecerdasan interpersonal yaitu: 1) penerapan pembiasaan 15 adab, saat daring dilakukan melalui dengan holiday challengs; 2) pemberian motivasi kepada siswa melalui kegiatan bercerita, saat pembelajaran daring pemberian motivasi hanya berupa nasihat; 3) pengelolaan kelas; 4) pendekatan secara mandiri maupun kelompok; 5) penerapan strategi pembelajaran yang melibatkan kerjasama antar siswa; dan 6) penerapan media pembelajaran visual maupun audio visual.
\end{abstract}

Kata Kunci: Kecerdasan Interpersonal; Siswa MI

\section{PENDAHULUAN}

Pendidikan memiliki kedudukan yang sangat menentukan dalam membangun pribadi setiap individu di masyarakat serta memajukan peradaban yang lebih maju. Salah satu tujuan dari pendidikan adalah mengembangkan kecerdasan. Terdapat berbagai jenis kecerdasan yang biasa disebut dengan kecerdasan majemuk. Teori kecerdasan majemuk ini dikemukakan oleh Howard Gardner yang dikenal dengan 
istilah multiple intellegences (Prasetyo dan Andriani, 2009:1). Howard Gardner dalam Munif dan Alamsyah (2012:79) juga menyatakan bahwa :

“ Otak manusia setidaknya menyimpan sembilan jenis kecerdasan, yaitu kecerdasan kinestetis, kecerdasan logis, kecerdasan matematis, kecerdasan spasialvisual, kecerdasan linguistic, kecerdasan musik, kecerdasan interpersonal, kecerdasan naturalis, dan kecerdasan intrapersonal".

Dari kesembilan jenis kecerdasan yang diungkapkan diatas, kecerdasan interpersonal merupakan salah satu kecerdasan yang berkembang dalam diri seseorang. Kecerdasan interpersonal merupakan kemampuan seseorang untuk berhubungan atau berinteraksi dengan orang-orang di sekitarnya sehingga bisa merasakan secara emosional, dapat memahami suasana hati, maksud serta kehendak orang lain (Munif Chatib, 2012:88). Kecerdasan interpersonal ini harus ditingkatkan dan dikembangkan dengan baik agar setiap individu dapat memahami dan bekerjasama dengan individu lain secara optimal, karena pada dasarnya manusia tidak dapat hidup sendiri.

Dewasa ini, permasalahan tentang kecerdasan sangat menarik untuk diperbincangkan. Sebab, masih banyak masyarakat yang beranggapan bahwa anak cerdas adalah anak yang memiliki nilai tinggi pada mata pelajaran tertentu seperti matematika, bahasa Inggris, sains, atau mata pelajaran yang lainnya. Selain itu, sistem budaya pendidikan kita selama ini masih belum begitu memperhatikan jenisjeniskecerdasan yang lain selain IQ. Sangat disayangkan bila anak usia dini dan anak usia SD mengalami tumpul psikososial atau kecerdasan interpersonal. Sebab, anak usia dini dan anak usia SD merupakan masa-masa pertumbuhan dan perkembangan bagidirinya, salah satunya yaitu perkembangan psikososial. Menurut Erikson dalam Rima Trianingsih (2018:31) perkembangan psikososial anak usia SD menekankan pada proses-proses sadar yang dialami anak ketika berinterkasi sosial. Karena pada umumnya, anak usia sekolah dasar memiliki karakteristik; a) senang bergerak, b) senang bermain, c) senang melakukan sesuatu secara langsung, dan d) senang bekerja dalam kelompok (IbadullahdanAni,2017:92). Sedangkan menurut penelitian dari Nana Sutarna, bahwa ada peningkatan kecerdasan interpersonal anak melalui pendekatan sosial.

Hasil observasi dan wawancara dengan salah satu guru pendidikan formal yang berada di daerah Klaten Utara padabulan November 2019, bahwa di sekolah tersebut masih terdapat siswa yang mengalami konflik interpersonal diantaranya seperti kurang bisa berbaur atau berinteraksi dengan teman maupun guru, dalam 
bekerjasama masih belum sesuai harapan dan mengalami gangguan komunikasi. Hal tersebut terlihat saat pembelajaran berlangsung, siswa cenderung pasif.

Guru memiliki peran yang sangat penting karena guru merupakan pengelola pembelajaran. Hal itu berarti bahwa guru merupakan salah satu komponen penting dalam pendidikan yang ikut bertanggung jawab dalam pembentukan serta perkembangan pribadi peserta didik. Maka, guru harus berupaya agar dapat meningkatkan serta mengembangkan kecerdasa nyang dimiliki oleh setiap peserta didik, salah satunya kecerdasan interpersonal.Peran guru dalam pendidikan sangat penting, sebab guru harus dapat memfungsikan dirinya sebagai pendidik yang multifungsi bagi perkembangan peserta didik dalam meningkatkan segala potensi yang dimilikinya. Dilihat dari sudut pandang psikologis, seorang guru itu sebagai; a) pakar psikologis pendidikan, b) seniman dalam hubungan antarmanusia, c) pembentuk kelompok, d) innovator dan e) petugas kesehatan mental (Moh.Surya, 2015:193).

Salah satu lembaga pendidikan formal yang mempunyai perhatian lebih terhadap kecerdasan interpersonal bagi peserta didiknya adalah SDIT Taqiyya Rosyida Kartasura. Berdasarkan wawancara di lapangan pada tanggal 9 Maret 2020 dengan ustadzah Risti selaku guru kelas VB dapat disimpulkan bahwa kecerdasan interpersonal siswa VB sudah terlihat baik. Hal ini terlihat dari siswa yang dapat bersosialisasi dengan baik dengan teman-temannya, seperti mampu bekerjasama, membantu teman yang mengalami kesulitan dalam memahami materi pembelajaran. Selain itu, dalam pembelajaran guru terlihat seimbang dalam memberikan tugas individu dan tugas kelompok untuk menemukan solusi permasalahan. Dari uraian permasalahan tersebut, maka penulis tertarik untuk menjadikan judul penelitian dengan judul “Upaya Guru Dalam Meningkatkan Kecerdasan Interpersonal Siswa Di SDIT Taqiyya Rosyida Kartasura Tahun Pelajaran 2019/2020".

\section{METODE PENELITIAN}

Penelitian ini menggunakan penelitian deskriptif kualitatif yang dilakukan di SDIT Taqiyya Rosyida Kartasura, pada bulan Maret sampai Juni 2020. Partisipan terdiri dari guru BK, guru pendamping VB, kepala sekolah di SDIT Taqiyya Rosyida Kartasura, 2 orang siswa kelas VB. Data dikumpulkan melalui observasi dan wawancara semi terstruktur secara langsung dan melalui whatsapp. 


\section{HASIL DAN PEMBAHASAN}

Hasil penelitian menunjukkan bahwa pemberdayaan kecerdasan interpersonal siswa kelas VB di SDIT Taqiyya Rosyida Kartasura yang pertama dilakukan melalui pembiasaan 15 adab. Salah satu pembiasaan adab yang dilaksanakan sebelum memulai pembelajaran di pagi hari yaitu pembiasaan adab ketika datang ke sekolah dan pembiasaan opening pagi. Adapun pembiasaan ketika datang ke sekolah (seperti mengucapkan salam, menyapa, bersalaman dengan guru, mengantri melepas sepatu di area yang telah ditentukan, meletakkan sepatu di rak dengan rapi, juga mengucapkan salam ketika masuk kelas kemudian bersalaman dengan teman). Sedangkan pembiasaan opening pagi, meliputi dari sholat dhuha berjamaah, murajaah atau tahfidzh bersama. Dari kegiatan tersebut, terdapat beberapa adab yang mesti dijalankan. Diantaranya yaitu; adab ketika berwudhu dan sholat (seperti antri tertib ketika akan berwudhu, masuk dan keluar masjid, serta diam/tidak berisik, mendengarkan kultum), adab masuk kelas (seperti antri tertib, mengucapkan salam, merapikan meja dan kursi sebelum duduk). Penerapan pembiasaan adab tersebut juga dilaksanakan pada saat pembelajaran daring melalui kegiatan "Holiday Challenge". Holiday Challenge merupakan tantangan bagi siswa selama liburan agar tetap melaksanakan kegiatan pembiasaan yang sering dilaksanakan disekolah. Tantangan tersebut berupa amalan-amalan seperti; Sholat fardhu tepat waktu, sholat Sunnah rawatib 12 raka'at (Qoblilah Subuh 2 rakaat, Qoblilah Dzuhur 4 raka'at, Ba' diyah Dzuhur 2 raka'at, Ba'diyah Maghrib 2 raka'at, dan Ba'diyah Isya' 2 raka'at), Sunnah Muakkad (Dhuha dan Tahajud), Sedekah, Tilawah Al-qur'an, Murajaah, Wirid/Dzikir (Al-Ma'tsurat pagi, Al-Ma'tsurat sore, Al- Ma'tsurat pribadi), Istighfar dan sholawat@100x, membantu orangtua, dan membaca buku. Holiday Challenge dilaksanakan dengan dampingan wali murid masing-masing kemudian mengisi check list pada lembar HolidayChallenge.

Selain pembiasaan 15 adab, langkah kedua yang dilakukan guru SDIT Taqiyya Rosyida Kartasura yaitu melalui pemberian motivasi. Salah satu cara untuk meningkatkan motivasi adalah dengan memberikan hadiah dan hukuman bagi siswa (Febianti 2018). Pemberian motivasi juga dilakukan guru tematik kelas VB SDIT Taqiyya Rosyida Kartasura dalam mengupayakan peningkatan kecerdasan interpersonal siswa. Pemberian motivasi diberikan pada saat awal sebelum pembelejaran dimulai, ditengah-tengah kegiatan pembelajaran, maupun diakhir 
kegiatan pembelajaran. Pada awal sebelum pembelajaran dimulai,guruselalu memberikan motivasi dengan bercerita kepada anak-anak. Motivasi yang disampaikan biasanya melalui dengan bercerita, berbagi pengalaman pribadi, atau nasihat-nasihat lainnya yang mendorong siswa ke hal-hal yang positif. Cerita yang disampikan biasanya berupa pengalaman pribadi. Guru menceritakan pengalaman pribadinya kepada siswa kemudian, siswa diminta untuk mendengarkan dan memahami dari cerita pengalaman tersebut. Selanjutnya,guru memberikan kesempatan kepada siswa untuk berpendapat mengenai nilai-nilai, nasihat atau pesan apa saja yang terkandung dalam cerita tersebut. Setelah itu guru memberikan penegasan ulang tentang nilai, nasihat atau pesan yang ada dalam cerita tersebut. Melalui kegiatan pembelajaran daring pemberian motivasi juga diberikan oleh guru kepada siswanya. Motivasi yang diberikan ketika daring yakni berupanasihat-nasihat dari guru supaya siswa tetaprajinbelajar,beribadah, menjaga kesehatan dan kebersihan lingkungan sekitar rumah. Pemberian motivasi tersebut dilakukan melalui sapaan lewat group whatsapp maupun pribadi dan melakukan video call kepada siswa.

Upaya selanjutnya yaitu dengan menerapkan pengelolaan kelas. Keterampilan dari guru untuk menciptakan kondisi belajar yang optimal dan mengembalikannya jika terjadi gangguan disebut sebagai keterampilan kelas (Sy 2014). Menurut Usman (2003) “Pengelolaan kelas yang efektif merupakanprasyarat

mutlak bagi terjadinya proses belajarmengajar yang efektif". Dalam mengupayakan peningkatan kecerdasan interpersonal siswa kelas VB SDIT Taqiyya Rosyida guru tematik juga melakukan pengelolaan kelas, diantaranya yaitu ruangan tempat berlangsungnya proses belajar mengajar dan pengaturan tempat duduk siswa. Ruangan belajar siswa terdapat hasil karya siswa yang di tempelkan di dindingdinding kelas, sehingga terlihat lebih menarik dan tidak membosankan. Di sudut ruangan juga terdapat pojok baca yang digunakan siswa untuk membaca buku sehingga membuat siswa merasa nyaman belajar di kelas. Pengaturan tempat duduk siswa dapat dilakukan secara berpasang-pasangan atau berkelompok sesuai dengan ketentuan yang telah dibuat oleh guru kelas, agar guru dapat sekaligus mengontrol tingkah laku pesertadidik

Melakukan pendekatan pada siswa merupakan langkah yang dilakukan oleh guru selanjutnya untuk mengembangkan kecerdasan interpersonal pada siswa. Pendekatan merupakan sudut pandang terhadap proses pembelajaran(Abdullah, 2017; Sanjaya, 
2008). Lebih lanjut Roy Kellen (1998) terdapat dua pendekatan dalam pembelajaran, yaitu teacher-centered approaches dan student-centered. Pendekatan kepada siswa selalu dilakukan oleh guru Tematik kelas VB di SDIT Taqiyya Rosyida. Pendekatan yang dilakukan biasanya berupa pendekatan kelompok dan pendekatan individu. Pendekatan kelompok itu biasanya dilakukan di dalam kelas saat proses pembelajaran berlangsung sedangkan pendekatan individu biasanya dilakukan di luar kelas dengan mendekati dan mendengarkan ungkapan siswa. Pada saat pembelajaran daring, guru kelas VB SDIT Taqiyya Rosyida Kartasura juga tetap melakukan pendekatan kepada siswa dengan cara melalui sapaan video call atau menyapa anak- anak di grup WhatsApp.

Langkah berikutnya adalah menerapkan strategi pembelajaran yang dapat menibatkan siswa untuk saling bekerjasama. Salah satu hal penting dalam pembelajaran adalah keteramoilan kerjasama (Rosita, 2015). Menurut Hamid (2011) kerja sama dapat mempercepat tujuan pembelajaran. Pembelajaran yang diterapkan pada Tematik di SDIT Taqiyya Rosyida Kartasura merupakan pembelajaran yang berpusat pada siswa. Guru memberikan kesempatan kepada siswa untuk terlibat langsung dalam proses pembelajaran. Dalam pembelajaran tematik, guru menggunakan strategi pembelajaran yang dapat melibatkan kerjasama antar siswa seperti; pemberian tugas secara berkelompok, berdiskusi, tutor sebaya dan bermain peran.

Pada saat pembelajaran daring, strategi yang melibatkan kerjasama tetap diberikan oleh guru kepada siswa agar dapat meningkatkan kecerdasan interpersonal siswa. Hanya bedanya, apabila saat pembelajaran langsung, guru menggunakan strategi yang melibatkan kerjasama antara siswa dengan siswa yang lainnnya. Sedangkan pada saat pembelajaran daring, guru menggunakan strategi yang melibatkan kerjasama antara siswa dengan orangtua siswa. Seperti melakukan kegiatan sehari-hari yan dilakukan oleh siswa membantu orangtua ketika dirumah.

Langkah terakhir yang dilakukan guru untuk meningkatkan kecerdasan interpersonal pada siswa yaitu dengan melibatkan media pembelajaran yang mendukung. Peranan media pembelajaran dalam proses belajar dan mengajar sangat penting (Tafonao, 2018). Menurut Briggs (1977) media pembelajaran merupakan sarana fisik untuk menyampaikan isi materi pembelajaran.Penggunaan media pembelajaran merupakan salah satu cara untuk membantu dan mempermudah guru dalam menyampaikan serta memahamkan materi pelajaran kepada siswa. Melalui 
penggunaan dan pemilihan media pembelajaran yang tepat oleh guru, juga dapat membantu meningkatkan kecerdasan interpersonal. Adapun media yang digunakan oleh guru tematik kelas VB SDIT Taqiyya Rosyida Kartasura yaitu media visual. Penggunaan media pembelajaran tetap diterapkan oleh guru kelas VB SDIT Taqiyya Rosyida Kartasura dalam pembelajaran daring ini. Media pembelajaran yang digunakan dapat berupa media audio visual seperti handphone danlaptop.

\section{KESIMPULAN}

Berdasarkan hasil penelitian dilakukan dapat disimpulkan bahwa upaya guru dalam meningkatkan kecerdasan interpersonal siswa kelas VB pada pembelajaran tematik di SDIT Taqiyya Rosyida tahun ajaran 2019/2020 yaitu: 1) melakukan penerapan pembiasaan 15 ; 2) pemberian motivasi; 3) melakukan pengelolaan kelas; 4)melakukan pendekatan kepada siswa baik pendekatan secara kelompok maupun pendekatan secara individu; 5) melakukan penerapan atau penggunaan strategi pembelajaran yang melibatkan kerjasama antar siswa; 6) menggunakan media pembelajaran visual.

\section{DAFTAR PUSTAKA}

Abdullah. (2017). Pendekatan dan model pembelajaran yang mengaktifkan siswa. Edureligia, 1(1): 45-62.

Arif, Rohman. (2009). Memahami pendidikan \& ilmu pendidikan. Yogyakarta: Laks Bang Mediatama.

Briggs, Leslie J. (1977). Instructional design, educational technology publications. Inc. New Jersey : Englewood Cliffs.

Febianti, Yopi Nisa. (2018). Peningkatan motivasi belajar dengan pemberian reward and punishment yang positif. Jurnal Edunomic, 6(2): 93-102

Hamid, Moh Sholeh. (2011). Metode edutainment. Jogjakarta: Diva Press.

Kellen, Roy. (1998). Effective teaching strategies- lesson from research and practice. Second edition. Australia: Social Science Perss.

Mohammad Surya. (2015). Psikologi guru konsep dan aplikasi dari guru untuk guru. Bandung: Alfabeta.

Munif Chatib dan Alamsyah Said. (2012). Sekolah anak-anak juara berbasis kecerdasan jamak dan pendidikan berkeadilan. Bandung: Mizan Media Utama.

Nurul, Fithriyah Hidayati dan Novianni Anggraini. (2015). Perkembangan peserta didik. Kartasura: Fataba Press.

Reza, Justinus Prasetyo dan Yeny Andriani. (2009). Multiply your multiple intelligences (melatih 8 kecerdasan majemuk pada anak dan dewasa). 
Yogyakarta: CV. Andi Offset.

Rosita, Ita. (2005). Meningkatkan kerja sama siswa melalui pembelajaran kooperatif tipe think pair share. Jurnal Formatif, 3(1): 1-10.

Sy, Irnes Jakli. (2014). Pengelolaan kelas dipandang dari perspektif psikologi. Journal Polingua, 3(2): 123-169.

Tafonao, Talizaro. (2018). Peranan media pembelajaran dalam meningkatkan minat belajar mahasiswa. Jurnal Komunikasi Pendidikan, 2(2): 103-114.

Usman, Moh. Uzer. (2003). Menjadi guru profesional. Bandung: Remaja Rosda Karya. 